\title{
Activation of Toll-like receptor 7 regulates the expression of IFN- $\lambda 1$, p53, PTEN, VEGF, TIMP-1 and MMP-9 in pancreatic cancer cells
}

\author{
FANG WANG $^{1}$, RUI JIN ${ }^{1}$, BING-BING ZOU ${ }^{2}$, LEI LI $^{1}$, FENG-WEI CHENG ${ }^{1}$, \\ XIN LUO ${ }^{1}$, XIAOPING GENG ${ }^{2}$ and SHENG-QUAN ZHANG ${ }^{1}$ \\ ${ }^{1}$ Department of Biochemistry and Molecular Biology, Anhui Medical University, Hefei, Anhui 230032; \\ ${ }^{2}$ Department of General Surgery, The First Affiliated Hospital of Anhui Medical University, Hefei, Anhui 230022, P.R. China
}

Received October 14, 2014; Accepted July 28, 2015

DOI: $10.3892 / \mathrm{mmr} .2015 .4730$

\begin{abstract}
Toll-like receptors (TLRs) are critical in the induction of the immune response in tumor development. TLR7 has previously been demonstrated to be associated with the development of pancreatic cancer, and the release of cytokines and chemokines from other types of cancer cell; however, the specific expression induced by TLR7 agonists in pancreatic cancer cells remains to be elucidated. The present study aimed to investigate the effects of the TLR7 agonist, gardiquimod, on ERK1/2 signaling pathway, and on the expression of genes involved in the pathogenesis of cancer, including phosphatase and tensin homolog deleted on chromosome 10 (PTEN), p53, type III interferon (IFN- $\lambda 1$ ), vascular endothelial growth factor (VEGF), matrix metalloproteinase 9 (MMP-9) and tissue inhibitor of metalloproteinase 1 (TIMP-1). The results demonstrated that activation of TLR7 upregulated the expression levels of certain genes to varying degrees; the expression levels of IFN- $\lambda 1$ and MMP-9 were increased by $\sim 3$ fold, whereas other genes (p53, PTEN, TIMP-1) were upregulated by $\sim 2$ fold, and VEGF was marginally upregulated after $10 \mathrm{~min}$. Furthermore, gardiquimod increased the expression levels of phosphorylated-extracellular signal-regulated kinase (ERK)1/2. In addition, PD98059, a specific inhibitor of ERK phosphorylation, inhibited the ability of gardiquimod to activate ERK1/2; consequently weakening the effect of gardiquimod on gene regulation. These findings indicated that the effect of TLR7 agonists, including gardiquimod, on gene expression in BxPC-3 pancreatic cancer cells was partly
\end{abstract}

Correspondence to: Professor Sheng-Quan Zhang, Department of Biochemistry and Molecular Biology, Anhui Medical University, 81 Meishan Road, Hefei, Anhui 230032, P.R. China

E-mail:sqz36@yahoo.com

Key words: Toll-like receptor 7, gardiquimod, BxPC-3, gene expression, mitogen-activated protein kinase/extracellular signal-regulated kinase associated with the mitogen-activated protein kinase-ERK1/2 signaling pathway.

\section{Introduction}

Toll-like receptors (TLRs), which exhibit homology with the Drosophila Toll protein (1), are crucial and central in the detection and elimination of invading pathogens (2). At present, 11 TLRs have been identified in mammals and 10 TLRs have been found in humans (1-3). TLR7 recognizes single-strand RNA or synthetic agonists, including imiquimod and its derivatives (4). Gardiquimod is a small molecule of the imidazoquinoline compounds and a derivative of imiquimod, which is reported as being recognized by TLR7 and is $\sim 10$ times more effective than imiquimod $(4,5)$. Activation of TLR7 initiates a signaling cascade, including MyD88 and nuclear factor- $\kappa \mathrm{B}$ signaling molecules, which consequently leads to activation of the downstream mitogen-activated protein kinase (MAPK) signaling pathway, secretion of cytokines and expression of co-stimulatory molecules (6).

Pancreatic cancer is one of the most aggressive and life threatening types of malignancy (7). Despite its low incidence in developed countries, pancreatic cancer is associated with poor survival rates (8). Due to its highly invasive and migratory potential, pancreatic cancer is ranked as the fourth most common cause of cancer-associated mortality in the United Kingdom (7). With the development of molecular biology, the association between immunotherapy and cancer, including pancreatic cancer, is improving $(7,9)$. It is well known that oncogenes and tumor suppressor genes control the proliferation, differentiation, migration, invasion and apoptosis of tumor cells (10). Interferon type III (IFN- $\lambda 1$ ), also termed interleukin (IL)-29 and similar to type I and type II IFNs, is a novel broad spectrum antiviral agent, which affects cell growth and differentiation, adjusts immune function and exerts several types of biological activity (11). p53 is a significant tumor suppressor, and inactivation of the p53 gene is important in tumor formation (12). Phosphatase and tensin homolog deleted on chromosome 10 (PTEN) is another key tumor suppressor, which is crucial in cell migration and regulates cell survival signaling via the phosphoinositide 3-kinase/Akt pathway (13). 
Vascular endothelial growth factor (VEGF) is the most effective promoter of vascular growth factors, which are associated with cancer growth and metastasis (14). Matrix metalloproteinase 9 (MMP-9) is a member of the zinc metalloproteinase family, which is important in cell invasion (15). Metastasis and tissue inhibitor of metalloproteinases (TIMPs) are inhibitors of MMPs, which are involved in innate immune defense and apoptosis $(16,17)$, and are commonly involved in the control of tumor development.

Several studies have demonstrated that activation of TLRs not only provides the possibility for the resolution of inflammation, but are also crucial in cancer $(18,19)$. Studies have reported that TLR7 is important in the pathogenesis of pancreatic cancer (20); however, the effect of TLR7 on gene expression remains to be elucidated. The present study aimed to observe the effects of the gardiquimod TLR7 agonist on the ERK1/2 signaling pathway, and on the expression of genes, including IFN- $\lambda 1$, p53, PTEN, VEGF, MMP-9 and TIMP-1.

\section{Materials and methods}

Reagents. The BxPC-3 human pancreatic cancer cell line was purchased from the Shanghai Cell Bank of Chinese Academy of Sciences (Shanghai, China). Gardiquimod was obtained from Invivogen, Inc. (San Diego, CA, USA). Antibodies targeting phosphorylated (p)-ERK1/2 were purchased from OriGene Technologies (Beijing, China), and those for ERK1/2 and $\beta$-actin were purchased from Santa Cruz Biotechnology, Inc. (Dallas, TX, USA). Primers for GAPDH, IFN- $\lambda 1$, p53, PTEN, VEGF, MMP-9 and TIMP-1 were obtained from Takara Biotechnology Co., Ltd. (Dalian China).

Cell culture. The BxPC-3 cells were cultured in RPMI 1640 medium supplemented with $10 \%$ fetal bovine serum (FBS), $100 \mathrm{U} / \mathrm{ml}$ penicillin and $100 \mathrm{U} / \mathrm{ml}$ streptomycin (Gibco; Thermo Fisher Scientific, Inc., Waltham, MA, USA) at $37^{\circ} \mathrm{C}$ in an atmosphere containing $5 \% \mathrm{CO}_{2}$.

Reverse transcription-quantitative polymerase chain reaction $(R T-q P C R)$. The BxPC-3 cells $\left(3 \times 10^{4} / \mathrm{ml}\right)$ were seeded into 24 -well plates at $37^{\circ} \mathrm{C}$ in a $5 \% \mathrm{CO}_{2}$ atmosphere for $48 \mathrm{~h}$. Following a $48 \mathrm{~h}$ culture, followed by 1 day of culture in FBS-free media, the cells were treated with gardiquimod $(3 \mu \mathrm{g} / \mathrm{ml})$ for a range of durations $(0,0.2,0.5,1,3,6,12$, 24 or 48 h). Total RNA was extracted from the cells using TRIzol ${ }^{\circledR}$ reagent (Invitrogen Life Technologies, Carlsbad, CA, USA). Reverse transcription of the RNA to cDNA was performed using a PrimeScript ${ }^{\mathrm{TM}}$ II 1st Strand cDNA Synthesis kit (cat. no. 6210A/B; Takara Biotechnology Co., Ltd.). The qPCR was subsequently performed using SYBR Premix Ex TaqII Perfect Real Time kit (Takara Biotechnology Co., Ltd.). The primer sequences are listed in Table I. The cDNA samples were amplified using the Applied Biosystems 7500 Real-Time PCR system (Applied Biosystems Life Technologies, Foster City, CA, USA) with the following cycling conditions: Pre-denaturation at $95^{\circ} \mathrm{C}$ for $5 \mathrm{sec}$, followed by 40 cycles of denaturation at $95^{\circ} \mathrm{C}$ for $5 \mathrm{sec}$, annealing at $95^{\circ} \mathrm{C}$ for $10 \mathrm{sec}$ and extension at $60^{\circ} \mathrm{C}$ for $60 \mathrm{sec}$. Operation dissolution curves were then constructed using SDS software version 2.0 (Applied Biosystems Life
Table I. Reverse transcription-quantitative polymerase chain reaction primer sequences used in the present study.

Gene Primer sequence

\section{GAPDH}

Forward

Reverse

5'AGATCATCAGCAATGCCTCCTG

IFN- $\lambda 1$

Forward 5'ATGGCATGGACTGTGGTCATG

Reverse

5'AAGTGGAAGAGTGTGCGGAAC

p53

Forward

5'AATAGGGTCTTGTTTCCGGCC

Reverse

5'CAGCCAAGTCTGTGACTTGCAC

VEGF

Forward

Reverse

5'AGACCATCGCTATCTGAGCAGC

MMP-9

Forward

5'CTCTACCTCCACCATGCCAAGT

5'TCGATTGGATGGCAGTAGCTG

Reverse

5'GGTGATTGACGACGCCTTTG

5'GGACCACAACTCGTCATCGT

TIMP-1

Forward

Reverse

5'TCTGCAATTCCGACCTCGTC

PTEN

Forward

5'CTGTTCCAGGGAGCCACAAA

Reverse

5'CAGCAGCTTCTGCCATCTCT

5'TGCTTTGAATCCAAAAACCTTACT

IFN- $\lambda 1$, interferon type III; VEGF, vascular endothelial growth factor; MMP-9, matrix metalloproteinases 9; TIMP-1, tissue inhibitor of metalloproteinase 1; PTEN, phosphatase and tensin homolog deleted on chromosome 10.

Technologies). The relative gene expression was calculated using the $2^{-\Delta \Delta C t}$ method.

Western blot analysis. The BxPC- 3 cells $\left(3 \times 10^{4} / \mathrm{ml}\right)$ were incubated in 24 -well plates at $37^{\circ} \mathrm{C}$ in a $5 \% \mathrm{CO}_{2}$ atmosphere for $48 \mathrm{~h}$. At a confluence of $70-80 \%$, the cells were cultured in FBS-free RPMI 1640 at $37^{\circ} \mathrm{C}$ in a $5 \% \mathrm{CO}_{2}$ atmosphere for 1 day, prior to treatment with gardiquimod $(3 \mu \mathrm{g} / \mathrm{ml})$ for $0,0.2,0.5,1,3,6,12,24$ or $48 \mathrm{~h}$. Following three washes with cold phosphate-buffered saline, the cells were treated with radioimmunoprecipitation assay buffer containing $1 \mathrm{mM}$ phenylmethylsulfonyl fluoride (Sigma-Aldrich, St. Louis, MO, USA) for $30 \mathrm{~min}$ in an ice-water bath. The protein concentration was determined and adjusted using a Bicinchoninic Acid kit (Sigma-Aldrich). Equal quantities of proteins $(10 \mu \mathrm{g})$ were separated using $12 \%$ gel electrophoresis (Sigma-Aldrich), and subsequently transferred to polyvinylidene fluoride membranes (EMD Millipore, Billerica, MA, USA). The membranes were then blocked with 5\% non-fat milk for $2 \mathrm{~h}$ at room temperature in Tris-buffered saline with Tween (TBST; Nanjing Sunshine Biotechnology Co., Ltd., Nanjing, China). Following washing with TBST, the membranes were incubated with monoclonal mouse anti-human anti- $\beta$-actin (1:500; sc-8342), polyclonal mouse anti-human anti-p-ERK1/2 
A

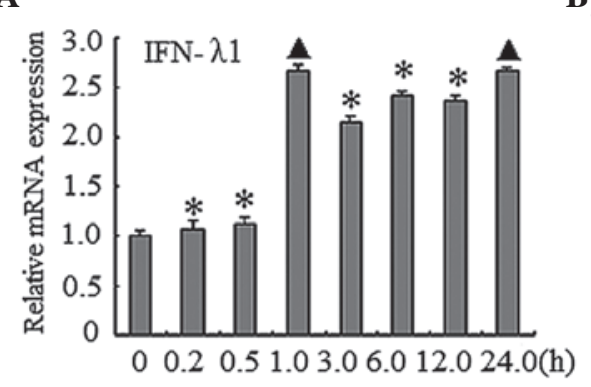

B

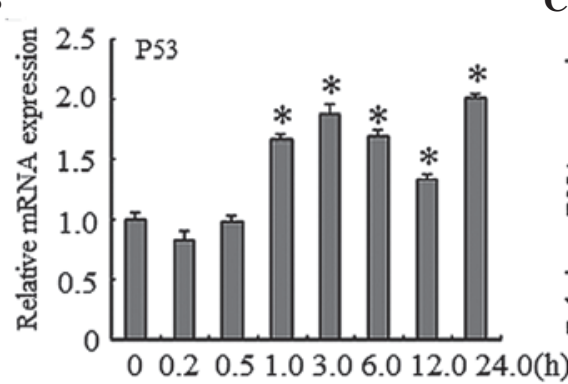

C

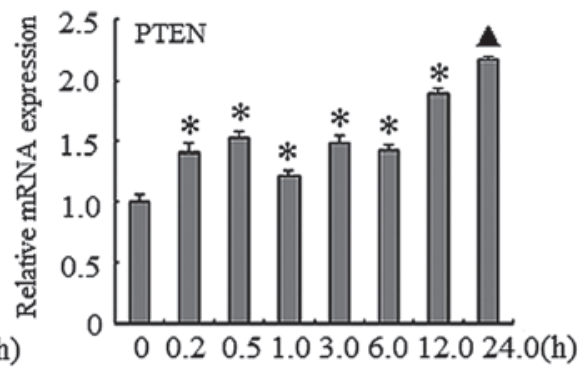

D

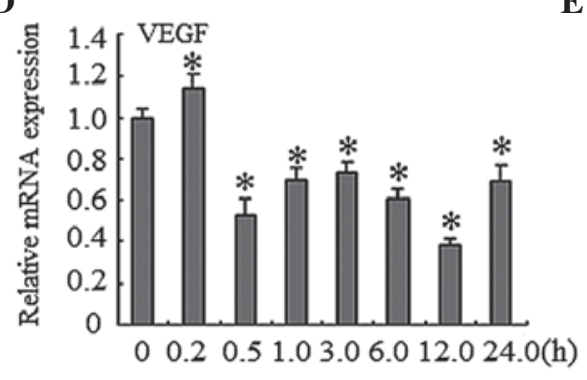

E

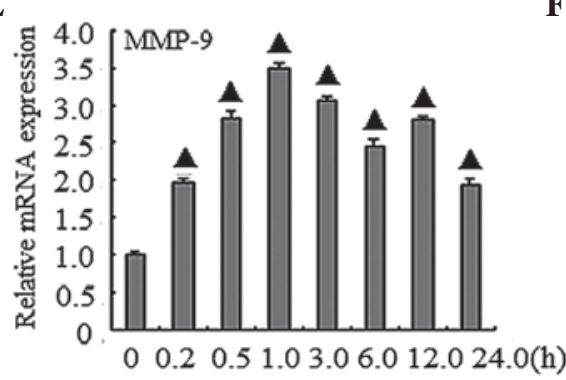

F 2.5 TIMP1

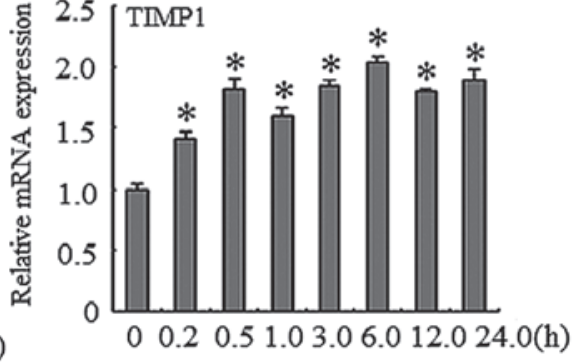

Figure 1. Gardiquimod induces the expression of several genes, as determined using RT-qPCR. The BxPC-3 human pancreatic cancer cells were treated with gardiquimod $(3 \mu \mathrm{g} / \mathrm{ml})$ for the indicated time-periods $(0,0.2,0.5,1.0,3.0,6.0,12$ and $24 \mathrm{~h})$. Total cellular RNA was extracted and was used to synthesize cDNA using reverse transcription. Subsequently, the mRNA expression levels of genes were determined using RT-qPCR, and GAPDH was used as a control. The mRNA expression levels (A) IFN- $\lambda 1$, (B) p53, (C) PTEN, (D) VEGF, (E) MMP-9 and (F) TIMP-1 were determined. The results were obtained from three separate experiments ( $\mathrm{P}<0.05$ and ${ }^{\wedge} \mathrm{P}<0.01$, vs. $0 \mathrm{~h}$ ); data are expressed as the mean \pm standard deviation. RT-qPCR, reverse transcription-quantitative polymerase chain reaction; INF, interferon; PTEN, phosphatase and tensin homolog deleted on chromosome 10; VEGF, vascular endothelial growth factor; MMP, matrix metalloproteinas; TIMP, tissue inhibitor of metalloproteinase.

(1:500; TA324783) and monoclonal mouse anti-human ERK1/2 (1:1,000; sc-135900) primary antibodies overnight at $4^{\circ} \mathrm{C}$. The membranes were then incubated with secondary antibodies, and the products were detected using enhanced chemiluminescence (SuperSignal-West Femto Trial kit; Pierce Biotechnology, Inc., Rockford, IL, USA). Quantity One 1-D image analysis software (Bio-Rad Laboratories, Inc., Hercules, CA, USA) was used to quantitatively analyze the densitometry of the blots. This experiment was repeated at least three times.

Statistical analysis. All experiments were repeated at least three times, with representative results presented, data are expressed at the mean \pm standard deviation. SPSS 13.0 software (SPSS, Inc., Chicago, IL, USA) was used for all statistical analyses. $\mathrm{P}<0.05$ was considered to indicate a statistically significant difference.

\section{Results}

Gardiquimod upregulates the expression of IFN- $\lambda 1$, p53, PTEN, VEGF, MMP-9 and TIMP-1 in BxPC-3 cells. To determine the effects of gardiquimod on gene regulation in BxPC3 cells, RT-qPCR was performed to analyze the mRNA expression levels of various genes. As shown in Fig. 1, these genes were upregulated at different time-points during the $24 \mathrm{~h}$ treatment period. Treatment with gardiquimod ( $3 \mu \mathrm{g} / \mathrm{ml}$ ) upregulated the expression levels of IFN- $\lambda 1$, with the highest peak detected at $24 \mathrm{~h}$, compared with the control group $(\mathrm{P}<0.01$; Fig. 1A). The expression levels of p53 and PTEN exhibited an increasing trend, reaching a peak at $24 \mathrm{~h}$, compared with the control group $(\mathrm{P}<0.05$; Fig. $1 \mathrm{~B}$ and $\mathrm{C})$.
The expression level of VEGF increased marginally at $10 \mathrm{~min}$; however, the expression levels reduced after $10 \mathrm{~min}$, with the lowest expression detected at $12 \mathrm{~h}(\mathrm{P}<0.01$; Fig. 1D). The expression of MMP-9 was highest at $1 \mathrm{~h}$, and the relative mRNA expression levels at $12 \mathrm{~h}$ were 3.5 -fold higher, compared with the control group $(\mathrm{P}<0.01$; Fig. $1 \mathrm{E})$. The lowest expression levels of MMP-9 were detected at $24 \mathrm{~h}$. In addition, the expression levels of TIMP-1 increased, compared with the blank control, with the peak level of expression detected at $6 \mathrm{~h}(\mathrm{P}<0.05$; Fig. $1 \mathrm{~F})$.

Gardiquimod induces the activation of ERK1/2 in BXPC-3 cells. In order to analyze whether gardiquimod induces activation of the ERK1/2 signaling pathway, western blot analysis was performed to detect alterations in the expression of ERK1/2. As shown in Fig. 2A and B gardiquimod activated the phosphorylation of ERK1/2 to p-ERK1/2 in a time-dependent manner in the BxPC-3 cells. The protein expression levels of p-ERK1/2 increased after $6 \mathrm{~h}$ treatment with gardiquimod, and this effect continued to $48 \mathrm{~h}$. However, the effects of gardiquimod over a longer treatment duration were not examined.

Gardiquimod-induced upregulation of downstream gene expression in BxPC-3 cells is partially dependent on the activation of ERK1/2. As shown in Fig. 2A and B, treatment with gardiquimod activated the ERK1/2 signaling pathway. In order to determine the association between activation of ERK1/2 and the expression of the activated genes, the cells were co-treated with gardiquimod $(3 \mu \mathrm{g} / \mathrm{ml})$ and the ERK1/2-specific inhibitor, PD98059 $(100 \mu \mathrm{M})$. The effects 

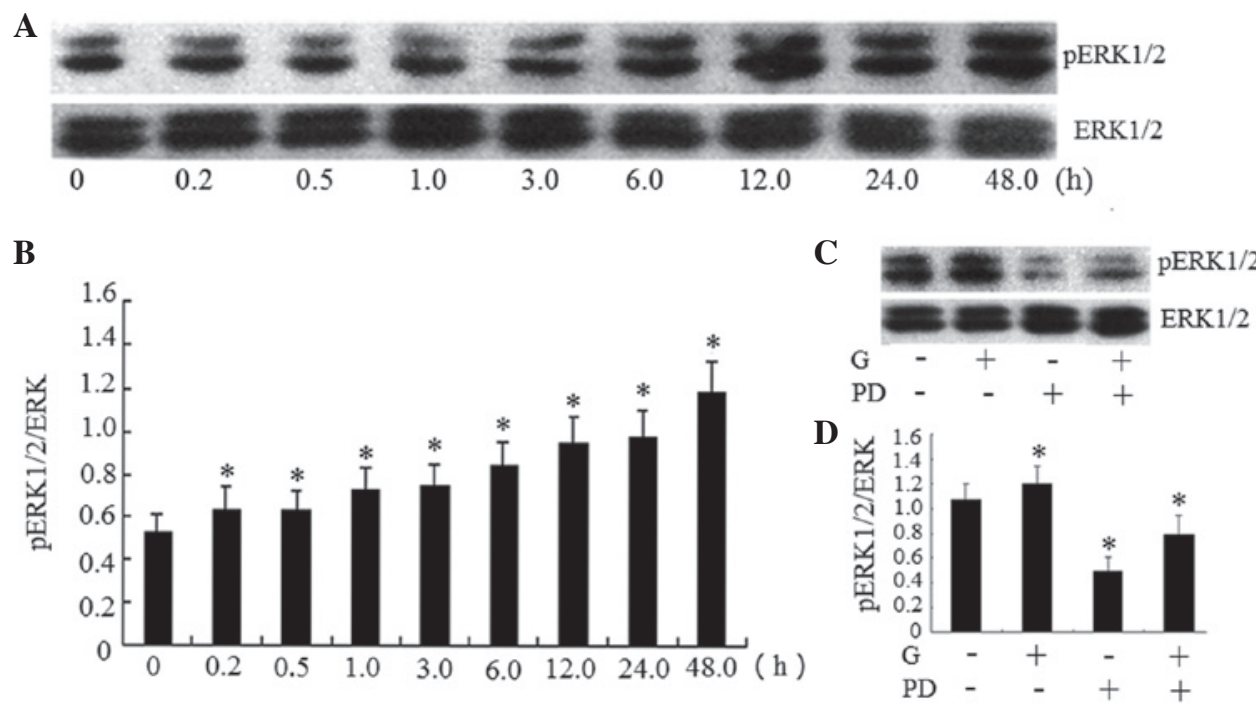

Figure 2. Activation of TLR7 by gardiquimod induces the phosphorylation of ERK1/2, which is inhibited by specific inhibitors. (A) BxPC-3 human pancreatic cancer cells were treated with gardiquimod $(3 \mu \mathrm{g} / \mathrm{ml})$ for different durations $(0,0.2,0.5,1.0,3.0,6.0,12 \mathrm{or} 24 \mathrm{~h})$. Total cellular proteins were extracted and were used to determine the protein expression levels of pERK1/2 using western blotting, with total ERK1/2 used as a control. (B) Band intensities of the western blot were determined using Quantity One software. The intensity of the target bands (pERK1/2) were normalized to the control bands (total ERK1/2). (C) Cells were pre-treated with PD98059 (100 $\mu \mathrm{mol} / \mathrm{l})$ for $1 \mathrm{~h}$ and treated with gardiquimod $(3 \mu \mathrm{g} / \mathrm{ml})$ for $6 \mathrm{~h}$. The expression levels of p-ERK1/2 and total ERK1/2 were detected using western blotting. (D) Band intensities of the western blot were determined using Quantity One software. The results are representative of three separate experiments; data are expressed as the mean \pm standard deviation; " $\mathrm{P}<0.05$ and ${ }^{\wedge} \mathrm{P}<0.01$ vs. 0 h. TLR, Toll-like receptor; ERK, extracellular signal-regulated kinase; pERK, phosphorylated ERK; G, gardiquimod; PD, PD98059.

A

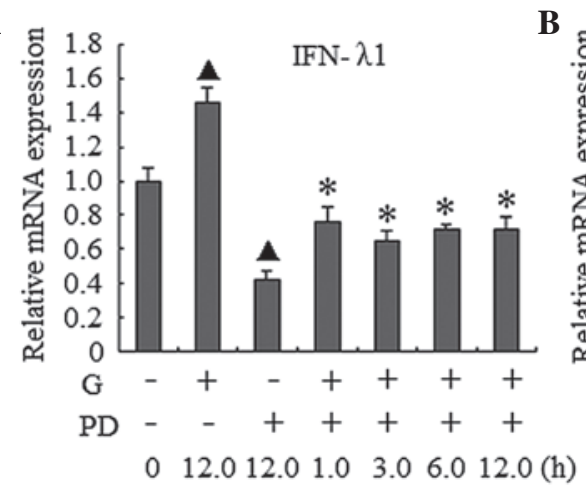

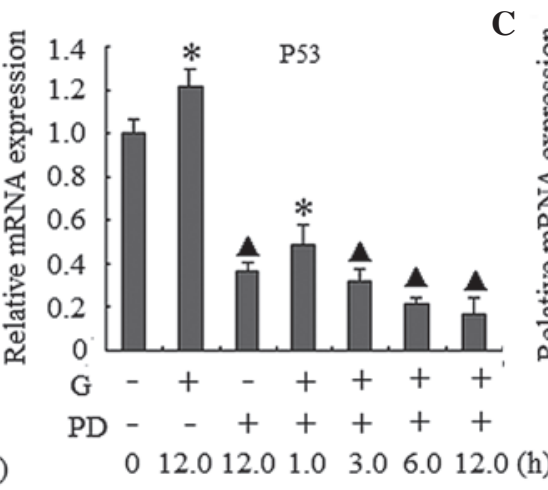

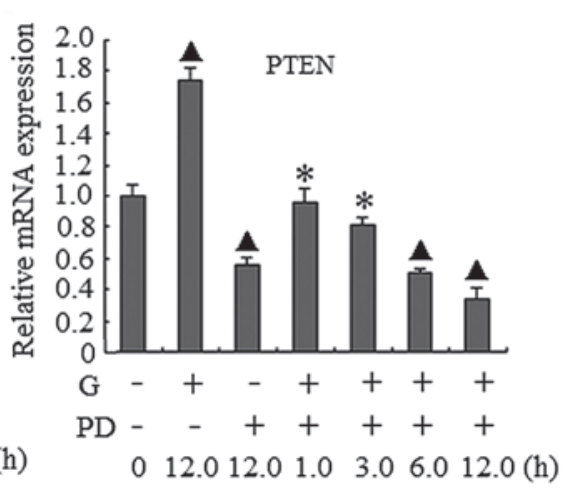

$\mathbf{F}$

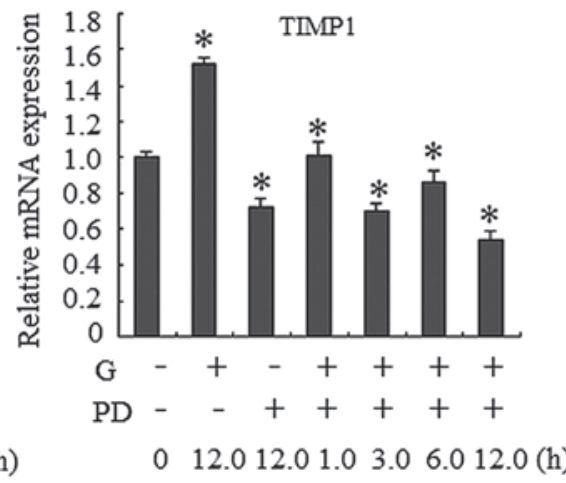

Figure 3. Effect of PD98059 (PD) on the gene expression of BxPC-3 human pancreatic cancer cells treated with gardiquimod (3 $\mu \mathrm{g} / \mathrm{ml})$. The BxPC-3 cells were pre-treated with PD $(100 \mu \mathrm{mol} / 1)$ for $1 \mathrm{~h}$, followed by treatment with $\mathrm{G}(3 \mu \mathrm{g} / \mathrm{ml})$ for the indicated durations. Reverse transcription-quantitative polymerase chain reaction was used to detect the mRNA expression levels of (A) IFN- $\lambda 1$, (B) p53, (C) PTEN, (D) VEGF, (E) MMP-9 and (F) TIMP-1. The results were obtained from three separate experiments; data are expressed as the mean \pm standard deviation; ${ }^{*} \mathrm{P}<0.05$ and ${ }^{\wedge} \mathrm{P}<0.01 \mathrm{vs} .0 \mathrm{~h}$. INF, interferon; PTEN, phosphatase and tensin homolog deleted on chromosome 10; VEGF, vascular endothelial growth factor; MMP, matrix metalloproteinase; TIMP, tissue inhibitor of metalloproteinase.

of PD98059 on p-ERK1/2 in the signaling pathway, and on the mRNA expression levels of IFN- $\lambda 1$, p53, PTEN, VEGF, MMP-9 and TIMP-1 were examined. As shown in
Fig. 2C and D the ERK1/2 signal pathway was inhibited by PD98059. The mRNA expression levels of the genes decreased markedly in the cells treated with PD98059 either 
alone or in combination with gardiquimod, compared with the cells in the gardiquimod-alone or blank control groups (Fig. 3). When the ERK1/2 signaling pathway was inhibited, the mRNA expression levels of MMP-9 were markedly decreased, regardless of whether the cells were treated with gardiquimod or not. The expression levels of IFN- $\lambda 1$, p53, PTEN and TIMP-1 also reduced, however, these reductions in expression were lower than that of MMP-9. These results suggested that the effect of gardiquimod on MMP-9 may be predominantly involved with the activation of ERK1/2; whereas the effects on IFN- $\lambda 1$, p53 and PTEN and MMP-9 and TIMP-1 may be only partially associated with the ERK1/2 pathway. In addition, as only marginal changes in the expression levels of VEGF were observed following treatment with gardiquimod, the regulation of VEGF by gardiquimod may not be associated with the ERK1/2 activation.

\section{Discussion}

TLRs are an important family of pattern-recognition receptors, which can initiate innate immunity and induce tumor cell death directly, or activate the adaptive immune system $(18,19)$. TLR7 can initiate the activation and maturation of immune cells, including dendritic cells and anti-tumor cytokines (21). In the present study, TLR7 was activated by the TLR7 agonist gardiquimod, which resulted in a series of changes in the expression of downstream factors.

According to previous studies, TLR7 exerts different functions on different cells. The activation of TLR7 can inhibit prostate cancer cells (22), however, TLR7 can also induce the development of cervical cancer (23). Therefore, TLR7 has different roles in immunotherapy (24). In previous studies, TLR7 was found to promote the expression of inflammatory cytokines, including IL-29 and IFN- $\lambda 1$, which in turn initiates the innate immune reaction and consequently suppresses the development of cancer $(25,26)$. In the present study, the results suggested that activation of TLR7 disturbed the development of pancreatic cancer through activation of the immune response. Certain anti-tumor genes were also observed to be upregulated by gardiquimod, including TIMP-1 and PTEN. By contrast, the expression of VEGF, which can promote proliferation, was marginally decreased following treatment with gardiquimod. These results indicated that TLR7 activation may have inhibited the progression of BxPC-3 pancreatic cancer cells. However, a study by Ochi et al (20) demonstrated that TLR7 activation promotes the development of pancreatic cancer cells carrying the G12D mutation; therefore, the effect of TLR7 on the development of pancreatic cancer requires further investigation.

The MAPK-ERK signaling pathway functions as a key factor in progression of the majority of types of cancer (27). Numerous studies have demonstrated that the activation of this pathway contributes to cancer cell proliferation; however, this pathway can also initiate the immune response, which defends against the transformation normal cells into cancer cells (28-30). Therefore, the activation of the MAPK-ERKsignaling pathway may have a pleiotropic effect on cancer cells, however the mechanism underlying the TLR7-induced activation of this pathway and the consequent effects on BxPC-3 cells remain to be fully elucidated, and the role of the MAPK-ERK pathway requires further investigation. Of note, this pathway is one of multiple pathways activated by TLR7, and the other pathways activated by gardiquimod also require investigation.

In conclusion, the present study demonstrated that TLR activation induced the expression of inflammatory factors and suppressed the expression of cancer-associated genes in BxPC-3 cells. In addition, these effects were partially dependent on activation of the MAPK-ERK pathway. These results may provide novel insight into the role of TLR7 in BxPC-3 pancreatic cancer cells.

\section{Acknowledgements}

The present study was supported by grants from the General Program of National Natural Science Foundation of China (grant no. 81271748), and the Foundation for Doctors, Anhui Medical University.

\section{References}

1. McGettrick AF and O'Neill LA: Toll-like receptors: Key activators of leucocytes and regulator of haematopoiesis. $\mathrm{Br}$ J Haematol 139: 185-193, 2007.

2. Sada T, Ota M, Katsuyama Y, Meguro A, Nomura E, Uemoto R, Nishide T, Okada E, Ohno S, Inoko $\mathrm{H}$ and Mizuki N: Association analysis of Toll-like receptor 7 gene polymorphisms and Behcet's disease in Japanese patients. Hum Immunol 72: 269-272, 2011.

3. Takeda K, Kaisho T and Akira S: Toll-like receptors. Annu Rev Immunol 21: 335-376, 2003.

4. Aspord C, Tramcourt L, Leloup C, Molens JP, Leccia MT, Charles $\mathrm{J}$ and Plumas J: Imiquimod inhibits melanoma development by promoting pDC cytotoxic functions and impeding tumor vascularization. J Invest Dermatol 134: 2551-2561, 2014.

5. Diebold SS, Kaisho T, Hemmi H, Akira S and Reis e Sousa C: Innate antiviral response by means of TLR7-mediated recognition of single-stranded RNA. Science 303: 1529-1531, 2004.

6. Ma F, Zhang J, Zhang J and Zhang C: The TLR7 agonists imiquimod and gardiquimod improve DC-based immunotherapy for melanoma in mice. Cell Mol Immunol 7: 381-388, 2010.

7. Steele CW, Jamieson NB, Evans TR, McKay CJ, Sansom OJ, Morton JP and Carter CR: Exploiting inflammation for therapeutic gain in pancreatic cancer. Br J Cancer 108: 997-1003, 2013.

8. Raimondi S, Maisonneuve P and Lowenfels AB: Epidemiology of pancreatic cancer: An overview. Nat Rev Gastroenterol Hepatol 6: 699-708, 2009.

9. Balkwill $\mathrm{F}$ and Mantovani A: Inflammation and cancer: Back to Virchow? Lancet 357: 539-545, 2001.

10. Wang X, Zhao J, Huang J, Tang H, Yu S and Chen Y: The regulatory roles of miRNA and methylation on oncogene and tumor suppressor gene expression in pancreatic cancer cells. Biochem Biophys Res Commun 425: 51-57, 2012.

11. Meager A,Heath A, Dilger P,Zoon K and Wadhwa M; Participants of the Collaborative Study: Standardization of human IL-29 (IFN- $\lambda 1$ ): establishment of a World Health Organization international reference reagent for IL-29 (IFN- $\lambda 1$ ). J Interferon Cytokine Res 34: 876-884, 2014.

12. Koido S,Homma S, Takahara A, Namiki Y, Tsukinaga S, Mitobe J, Odahara S, Yukawa T, Matsudaira H, Nagatsuma K, et al: Current immunotherapeutic approaches in pancreatic cancer. Clin Dev Immunol 2011: 267539, 2011.

13. Ma J, Sawai H, Matsuo Y, Ochi N, Yasuda A, Takahashi H, Wakasugi T, Funahashi H, Sato M and Takeyama H: IGF-1 mediates PTEN suppression and enhances cell invasion and proliferation via activation of the IGF-1/PI3K/Akt signaling pathway in pancreatic cancer cells. J Surg Res 60: 90-101, 2010.

14. Shi Y, Tong M, Wu Y, Yang Z, Hoffman RM, Zhang Y, Tian Y, Qi M, Lin Y, Liu Y, et al: VEGF-C ShRNA inhibits pancreatic cancer growth and lymphangiogenesis in an orthotopic fluorescent nude mouse model. Anticancer Res 33: 409-417, 2013.

15. Bauvois B: New facets of matrix metalloproteinases MMP-2 and MMP-9 as cell surface transducers: outside-in signaling and relationship to tumor progression. Biochim Biophys Acta 1825: 29-36, 2012. 
16. Lorente L, Martín MM, Solé-Violán J, Blanquer J, Labarta L, Díaz C, Borreguero-León JM, Orbe J, Rodríguez JA, Jiménez A and Páramo JA: Association of sepsis-related mortality with early increase of TIMP-1/MMP-9 ratio. PLoS One 9: e94318, 2014.

17. Zampini R, Argañaraz ME, Miceli DC and Apichela SA: Detection of the matrix metalloproteinases MMP-2 and MMP-9 and tissue inhibitors of metalloproteinases TIMP-1 and TIMP-2 in llama (Lama glama) oviduct. Reprod Domest Anim 49: 492-498, 2014.

18. Fehres CM, Bruijns SC, van Beelen AJ, Kalay H, Ambrosini M, Hooijberg E, Unger WW, de Gruijl TD and van Kooyk Y: Topical rather than intradermal application of the TLR7 ligand imiquimod leads to human dermal dendritic cell maturation and CD8+ T-cell cross-priming. Eur J Immunol 44: 2415-2424, 2014.

19. Yu X, Wang Y, Zhao W, Zhou H, Yang W and Guan X: Toll-like receptor 7 promotes the apoptosis of THP-1-derived macrophages through the CHOP-dependent pathway. Int J Mol Med 34: 886-893, 2014

20. Ochi A, Graffeo CS, Zambirinis CP, Rehman A, Hackman M, Fallon N, Barilla RM, Henning JR, Jamal M, Rao R, et al: Toll-like receptor 7 regulates pancreatic carcinogenesis in mice and humans. J Clin Invest 122: 4118-4129, 2012

21. Zhu J, Lai K, Brownile R, Babiuk LA and Mutwiri GK: Porcine TLR8 and TLR7 are both activated by a selective TLR7 ligand, imiquimod. Mol Immunol 45: 3238-3243, 2008.

22. Han JH, Park SY, Kim JB, Cho SD, Kim B, Kim BY, Kang MJ Kim DJ, Park JH and Park JH: TLR7 expression is decreased during tumour progression in transgenic adenocarcinoma of mouse prostate mice and its activation inhibits growth of prostate cancer cells. Am J Reprod Immunol 70: 317-326, 2013.
23. Li L, Cheng FW, Wang F, Jia B, Luo X and Zhang SQ: The activation of TLR7 regulates the expression of VEGF, TIMP1, MMP2, IL-6 and IL-15 in Hela cells. Mol Cell Biochem 389: 43-49, 2014.

24. Medzhitov R, Preston-Hurlburt P and Janeway CA Jr: A human homologue of the Drosophila Toll protein signals activation of adaptive immunity. Nature 388: 394-397, 1997.

25. Harvey RD and Morgan ET: Cancer, inflammation, and therapy: Effects on cytochrome p450-mediated drug metabolism and implications for novel immunotherapeutic agents. Clin Pharmacol Ther 96: 449-457, 2014.

26. Coussens LM and Werb Z: Inflammation and cancer. Nature 420: 860-867, 2002.

27. Wang C, Cigliano A, Delogu S, Armbruster J, Dombrowski F, Evert M, Chen X and Calvisi DF: Functional crosstalk between AKT/mTOR and Ras/MAPK pathways in hepatocarcinogenesis: Implications for the treatment of human liver cancer. Cell Cycle 12: 1999-2010, 2013.

28. Pivarcsi A, Müller A, Hippe A, Rieker J, van Lierop A, Steinhoff M, Seeliger S, Kubitza R, Pippirs U, Meller S, et al: Tumor immune escape by the loss of homeostatic chemokine expression. Proc Natl Acad Sci USA 104: 19055-19060, 2007.

29. Yang HT, Cohen P and Rousseau S: IL-1beta-stimulated activation of ERK1/2 and p38alpha MAPK mediates the transcriptional up-regulation of IL-6, IL-8 and GRO-alpha in HeLa cells. Cell Signal 20: 375-380, 2008.

30. Haydn JM, Hufnagel A, Grimm J, Maurus K, Schartl M and Meierjohann S: The MAPK pathway as an apoptosis enhancer in melanoma. Oncotarget 5: 5040-5053, 2014. 